\title{
Pesticide usage and occupational hazards among farmers working in small-scale tomato farms in Cameroon
}

\author{
Ayuk B. Tambe ${ }^{1,2^{*}} \mathbb{D}$, Baleba M. R. Mbanga ${ }^{1}$, Dapi L. Nzefa ${ }^{3}$ and Medoua G. Nama ${ }^{1}$
}

\begin{abstract}
Background: Agriculture is undoubtedly the backbone of the Cameroonian economy, and other economic activities thrive only if production in this sector is assured. It has been estimated that approximately 25 million agricultural workers worldwide experience unintentional pesticide poisoning yearly. Unfortunately, limited information exists about the health and safety of the farmers. The aim of this study was to describe the occupational health and safety (OHS) conditions of farmers working on small-scale tomato farms in the western region of Cameroon.

A cross-sectional research method was used to collect data from tomato farmers in May 2017, using a questionnaire developed by the research team.

Results: A total of 104 tomato farmers from small-scale farms participated in the study. The analysis revealed that the occupation is male-dominated (86.5\%). The training and use of personal protective equipment (PPE) among farmers were rare (35.6\%), and farmers were mostly exposed to chemical hazards. The farmers reported the following workrelated health problems: skin irritation, backache, impairment of the central nervous system (CNS), visual problems, and respiratory difficulties.
\end{abstract}

Conclusions: The OHS conditions on small-scale tomato farms are mostly poor, thus predisposing farmers to the risk of work-related health problems. Exposure to occupational hazards can be significantly reduced if the required PPE are available and efficiently used.

Keywords: Tomato farmers, Pesticides, Occupational health and safety, Cameroon

\section{Introduction}

Agriculture is a vital economic sector in Cameroon, especially since an estimated $45 \%$ of Cameroon's gross domestic product (GDP) depends on it [1]. The traditional food crop is part of an integrated household-farming system [2]. Therefore, crop destruction would paralyse many households; subsequently, farmers rely on pesticide use for pest control due to its assumed lower cost. However, according to the World Health Organization (WHO) standards [3], only pesticides that are safe to farmers and farm-workers should be used.

\footnotetext{
*Correspondence: ayuk.betrand@yahoo.com

${ }^{1}$ Centre for Food and Nutrition Research, Institute of Medical Research and Medicinal Plant Studies (IMPM), MINRESI, P.O. Box 13033, Yaoundé, Cameroon

${ }^{2}$ Division of Human Nutrition, Department of Global Health, Stellenbosch University, P.O. Box 241, Cape Town, South Africa

Full list of author information is available at the end of the article
}

Pesticide use has increased over the past 20 years, the highest identified in low-income countries starting from a low base such as Cameroon, Ethiopia, and Burkina Faso with an 8- to 50-fold increase [4]. In middleincome countries like China, Argentina, Brazil, and Thailand pesticide use increased from three- to eightfold while it has been stable, or even decreasing, in highincome countries like in the USA, Germany, Japan, and Denmark [4]. Even though there has been a rise in pesticide use in developing countries, very limited information exists about the health and safety of the farmers.

Pesticides used on tomato farms are classified according to their target organisms, chemical class, and toxicity. According to their target organism, they are divided into insecticides, fungicides, herbicides, rodenticides, and bactericides. Previous studies have revealed that the most used pesticides in low-income countries like Cameroon are insecticides, contrary to herbicides 
which are mostly used at the global level, given that weeding is done manually in Cameroon [5-8]. According to their chemical classes, the most common pesticides used are organophosphates, organochlorides, carbamates, pyrethroids, and dipyridils.

WHO has divided pesticides into the toxicity classes Ia, Ib, II, III, U in decreasing toxicity, and $\mathrm{O}$ being the sign for obsolete pesticides. Obsolete pesticides are defined as those pesticides that can no longer be used for their intended purpose and therefore must be disposed of. These include, among others, banned, outdated, and deteriorated pesticides according to the Food and Agriculture Organization (FAO) [9]. Although a great number of toxic pesticides under the WHO classes Ia and Ib and some pesticides belonging to class II and class $\mathrm{O}$ have been restricted for use in several countries, they are still extensively used in middle- and low-income countries. The use of these restricted pesticides is due to its broad spectrum application, costs, and ease of use [6]. The intensive use of pesticides on tomato farms seems to ensure the best-quality produce which guarantees good prices for farmers and excellent sales for vendors [10].

Work-related pesticide poisoning has increased globally, especially in less-developed countries [11]. It has been estimated that yearly about 25 million agricultural workers globally experience unintentional pesticide poisoning [12]. The main obstacle to control and prevent work-related pesticide poisoning is that the scope and magnitude of this issue often remains uncharacterised, especially in an underserved population such as farmers [13]. In Cameroon, pesticide-poisoning data are often reported as incidence data from hospitals. Contrary to workers in large agricultural companies who may receive safety training on the use of pesticides to reduce exposure, the majority of tomato farmers in Cameroon work independently, only having small plots of farmland. They may apply pesticides using simple backpack style applicators without adequate knowledge of the basic safety measures.

The aim of this study was to describe the occupational health and safety (OHS) conditions in the use of pesticides among farmers working in small-scale tomato farms in the western region of Cameroon. The specific objectives of the research were to collect the demographic profile of the farmers, identify the training and use of personal protective equipment (PPE), and report work-related complaints among small-scale tomato farmers.

\section{Materials and methods}

\subsection{Survey participants}

A quantitative cross-sectional survey was conducted to collect data from 104 small-scale tomato farmers relating to their demographic profile, OHS knowledge and practice on the use of pesticides, and the occupational health complaints. The farmers were interviewed at their various farms to conduct an on the spot inspection on the use of pesticides.

\subsection{Study area}

The western region is a major tomato-growing region in Cameroon, and the overuse of pesticides to manage pests and diseases has been observed. Although these chemicals increase crop yields, they can also cause health and environmental hazards when used irresponsibly.

\subsection{Data collection}

The data collection was done in May 2017 by the research team. The farmers were interviewed at farms, in French language. Inclusion criteria were tomato farm workers living in the western region of Cameroon and working in small-scale farms in 2017. A total of 106 tomato farmers were eligible for the study. A snowball sampling method was used to gather information from all eligible participants. In this case, referrals were asked from already identified participants, given the lack of database, as most of the workers are presumably unregistered.

Data were collected through a well-structured interviewer-led questionnaire and on-site observations to complement responses got from the use of the questionnaire. The questionnaire consisted of three sections, namely the demographic profile, farmers' OHS knowledge and practice on the use of pesticides, and the occupational health complaints.

The demographic profile included age, gender, marital status, education level, and work experience. The knowledge and practice of participants were measured through seven items relating to the training on the use of pesticides, safety boots, safety glasses, gloves, a nose mask, raincoats, and cleaning the body immediately after the use of pesticides. In this scale, each item had more than one correct answer, and all the correct answers in each item were summarized to give one point. Thus, the total score of knowledge and practice ranged from 0 to 7. Regarding occupational health complaints, five questions were asked concerning the following items: skin irritation, backache, nervous system injury, visual problems, and respiratory difficulty. Occupational health complaints were evaluated based on a 2-point Likert scale (yes $=1$ and no $=0$ ). The occupational health complaints' score ranged from 0 to 5 .

The farmers were interviewed in their various farms to conduct an on the spot inspection on the use of pesticides. The questionnaire was pre-tested on five farmers to ensure the language used was appropriate and could be understood by all farmers. The feedback was incorporated into the final questionnaire used in this study. 


\subsection{Data analysis}

The data collected was coded, entered, cleaned, and analysed using Epi Info version 7. The frequencies were established for categorical data. Univariable analysis using the chi-square test to verify the relationship between the safe use of PPE and the gender of the farmers was used. The Pearson chi-square test was used mainly due to the fact that the dependent or independent variables had two categories. The accepted level of significance for determinants of practice of OHS was set at 0.05 .

\section{Results}

A total of 106 tomato farmers were initially surveyed and interviewed. Two questionnaires were rejected since the participants did not complete the questionnaires as required. The results reported are based on the data collected from 104 tomato farmers.

\subsection{Demographic details}

The current study analysis indicated that the average age of the participants was $38.0 \pm 10.3$ years. The majority of the farmers were between 31 and 40 years, and of that group, $86.5 \%$ was male. Most of the participants were married $(81.7 \%)$ and had at least secondary education (62.5\%). The average work experience of the farmers was $4.8 \pm 1.2$ years with the majority of participants having work experience of between 4 and 6 years $(83.7 \%$, Table 1$)$

\subsection{Participants' farm sizes and description of products cultivated}

The tomato farms were generally small, varying from 0.3 to 4.0 hectares (ha) with an average size of 1.1 ha. The majority (79.8\%) of these farmers owned farms less than 1 ha as compared to $20.2 \%$ who owned more than 1 ha of the tomato farm. The main restraining factors for farmers to cultivate large surface areas were labour and capital. Although tomato fruit was the main product, most of these farmers also cultivated other crops such as peppers, green peppers, water melons, beans, green beans, green spices, carrots, maize, groundnuts, potatoes, cocoa, bananas, and cucumbers.

\subsection{Pesticide use in tomato farming}

The analysis revealed that 18 pesticides were used on tomatoes by farmers in the western region of Cameroon with most $(n=15)$ of the pesticides enlisted on the homologated list of pesticides published by the Cameroon Ministry of Agriculture and Rural Development (MINADER). Three of these pesticides were not included in the homologated list. Out of the 15 pesticides enlisted on the Cameroon homologated list, 11 pesticides were obsolete, and four pesticides were not obsolete. The study analysis indicated that the most used fungicides in the
Table 1 Socio-demographic characteristics of farmers working in small-scale tomato farms, Cameroon, 2017 ( $N=104)$

\begin{tabular}{lll}
\hline Variables & Frequency $N=104$ & Percentage \\
\hline Gender & & \\
Male & 90 & 86.5 \\
Female & 14 & 13.5 \\
Marital status & & \\
Single & 19 & 18.3 \\
Married & 85 & 81.7 \\
Age & & \\
$21-30$ & 31 & 29.8 \\
$31-40$ & 32 & 30.8 \\
$41-50$ & 28 & 26.9 \\
51-57 & 13 & 12.5 \\
Level of education & & \\
No formal & 3 & 2.9 \\
Primary level & 25 & 24.0 \\
Secondary level & 65 & 62.5 \\
Vocational training & 9 & 8.7 \\
Tertiary & 2 & 1.9 \\
Work experience & & \\
1-3 & 17 & 16.3 \\
$4-6$ & 87 & \\
\hline
\end{tabular}

study sites were maneb, mancozeb, metalaxyl, carbendazim, and thiophanate-methyl, while the most used insecticides were cypermethrin, imidacloprid, lambda cyhalothrin, chlorpyriphos-ethyl, endosulfan, and dimethoate. In addition, the frequently used herbicides were glyphosate, paraquat, and pendimethalin. All of the pesticides used are classified under the WHO chemical active ingredients hazards category class II (moderately hazardous) and class III (unlikely to cause hazards), as demonstrated in Table 2. The choice of pesticide used varied with season, area, and individual farmer.

\subsection{The use and storage of pesticides by tomato farmers}

The duration between spraying pesticides and harvesting the tomato fruit for consumption ranged between 1 and 30 days, depending on the farmer and the type of pesticide used. The mean duration was 9.0 days. Regarding the storage of pesticides, $69.2 \%$ stored their pesticides on their farms, $26.9 \%$ stored the pesticides in their homes, and $26.9 \%$ stored the pesticides in their warehouse. Regarding the management of empty pesticide containers/ sachets, $53.8 \%$ farmers discarded the waste on their farms, as compared to $37.6 \%$ who burned the containers themselves. Just $4.8 \%$ of farmers reported they handed their empty pesticide containers/sachets to environmentalists for proper management. Nevertheless, some 
Table 2 The major pesticides used by tomato farmers in the west region of Cameroon, 2017

\begin{tabular}{|c|c|c|c|c|}
\hline Pesticides & Commercial name & Active ingredients (Al) & Chemical group & $\begin{array}{l}\text { WHO chemical Al } \\
\text { hazard classification }\end{array}$ \\
\hline \multirow[t]{5}{*}{ Fungicide } & PLANTINEB 80 WP & Maneb 80\% & Carbamate & $\|$ \\
\hline & DITHANE M $45^{\mathrm{a}}$, IVORY $80^{\mathrm{a}}$ & Mancozeb 640, 800 g/kg & Carbamate & $\|$ \\
\hline & APRON 42 DS $^{a}$ & Metalaxyl $80 \mathrm{~g} / \mathrm{kg}$ & Acylalanine & $\|$ \\
\hline & CLEARY'S $3336^{\mathrm{b}}$ & Carbendazim & Benzimidazole & $\|$ \\
\hline & TOPSIN M ${ }^{b}$ & Thiophanate-methyl & Benzimidazole & $\|$ \\
\hline \multirow[t]{5}{*}{ Insecticides } & $\begin{array}{l}\text { AKITO } 25 \text { EC, CIGOGNE } 12 \text { EC }^{a} \text {, CYPALM } 50 \\
\text { EC } C^{a} \text {, CYPERCAL } 50 \text { EC, CYPLANDIM } 260 \text { EC }^{\text {a }}\end{array}$ & Cypermethrin 12, 20, 50, $100 \mathrm{~g} / \mathrm{l}$ & Pyrethroid & $\|$ \\
\hline & PARASTAR 40EC & Imidaclopride $20 \mathrm{~g} / \mathrm{l}$ + lambdacyhalothrine $20 \mathrm{~g} / \mathrm{l}$ & Pyrethroid & $\|$ \\
\hline & PYRIFORCE ${ }^{\mathrm{a}}$ & Chlorpyrifos-ethyl $600 \mathrm{~g} / \mathrm{l}$ & Organophosphorus & $\|$ \\
\hline & THIONEX 35R EC ${ }^{a}$ & Endosulfan $350 \mathrm{~g} / \mathrm{l}$ & Organochlorine & $\|$ \\
\hline & DIMEX 400EC & Dimethoate $400 \mathrm{~g} / \mathrm{l}$ & Organophosphorus & $\|$ \\
\hline \multirow[t]{3}{*}{ Herbicide } & Gramoxone $^{a}$ & Paraquat $200 \mathrm{~g} / \mathrm{l}$ & Bipyridylium & $\|$ \\
\hline & ROUND UP $360^{a}$ & Glyphosate 360 g/l & Glycine derivative & III \\
\hline & Corral Gt & Pendimethalin $500 \mathrm{~g} / \mathrm{L}$ & Dinitroaline & III \\
\hline
\end{tabular}

$\bar{a}=$ Obsolete. $\dagger={ }^{b}$ Not enlisted on the Cameroon homologated list of pesticides. WHO classification class $\mathrm{II}=$ moderately hazardous and III $=$ slightly hazardous

(3.5\%) farmers used the empty pesticide sachets as packaging for tomatoes, see Fig. 1.

\subsection{Training and safe practice of OHS among tomato farmers}

Table 3 shows that $35.6 \%$ of the participants were trained on the use of PPE, while $64.4 \%$ have not received any form of OHS training. Thirteen participants (12.5\%) reported they used safety boots during the spraying of pesticides as compared to $87.5 \%$ who did not. The use of safety glasses was also assessed, $31.7 \%$ used safety glasses when required while $68.3 \%$ did not. Regarding the use of gloves, the analysis revealed that $49.0 \%$ used gloves during work as compared to $51.0 \%$ who did not. Only $35.6 \%$ of the participants put on raincoats during the spraying of pesticides while $64.4 \%$ did not wear raincoats or any other form of protective clothing. The majority (99.0\%) of the workers did not clean up their body immediately after using pesticides.

\subsection{Participants' work-related health complaints}

Regarding participants' work-related health problems/ complaints, $24 \%$ complained of skin irritation after spraying of pesticides, $10.6 \%$ complained of backache, $9.6 \%$ reported nervous system injuries such as headache and dizziness, $16.3 \%$ reported visual problems, and $4.8 \%$ complained of respiratory difficulties (see Table 4).

\subsection{The association between the participant's gender and} the practice of OHS $(N=104)$

Only the use of safety boots $(p=0.044)$ and the use of nose masks $(p=0.004)$ were significantly associated with the gender of the farmers (Table 5).

\section{Discussion}

This study aimed at investigating the OHS conditions on the use of pesticides among farmers working in smallscale tomato farms in the western region of Cameroon.

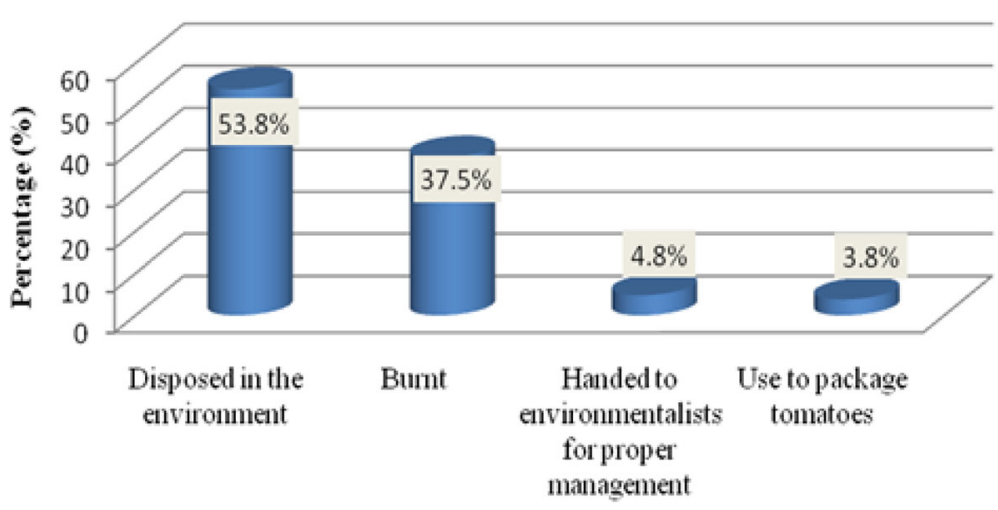

Fig. 1 The management of empty pesticide sachets/containers 
Table 3 Participants' practices relating to the training and use of PPE, Cameroon, $2017(N=104)$

\begin{tabular}{|c|c|c|}
\hline Variables & $\begin{array}{l}\text { Yes } \\
N(\%)\end{array}$ & $\begin{array}{l}\text { No } \\
N(\%)\end{array}$ \\
\hline Received training on the use of pesticides & $37(35.6)$ & $67(64.4)$ \\
\hline Use of safety boots & 13(12.5) & $91(87.5)$ \\
\hline Use of safety glasses & $33(31.7)$ & $71(68.3)$ \\
\hline Use of gloves & $51(49.0)$ & $53(51.0)$ \\
\hline Use of nose masks & $69(66.3)$ & $35(33.7)$ \\
\hline Use of raincoats & $37(35.6)$ & $67(64.4)$ \\
\hline Clean up the body immediately after the use of pesticides & $1(1.0)$ & 103(99.0) \\
\hline
\end{tabular}

The majority of the farmers were males in their active age. This implies that the workforce in the small-scale tomato farming in the study sites is mostly male-dominated. This might be due to the hard and labourious work required, which might naturally limit the involvement of females and elderly people. The gender of the farmers also affected the use of safety boots and nose masks $(p<0.05)$.

These results confirmed the findings of Tarla et al. [14] who reported that the majority of small-scale tomato farmers in the western region of Cameroon were males. Women assisted their husbands in activities that did not require a lot of energy, such as transplanting and harvesting of tomato fruits. Similarly, another study conducted by Tandi et al. [15] in evaluating the perception of small-scale tomato cultivators on pesticide usage and practices in Buea, in the southwest region of Cameroon revealed that $96.7 \%$ of tomato farmers were males.

Regarding the level of education, the study revealed that secondary school was the highest level of education attained by the majority of tomato farmers in the study area. It has been argued that being educated increases access to information, training, and communication materials, enables a better awareness of various workplace hazards, and ensures an understanding of safe work procedures and a better propensity to develop a positive attitude towards OHS at work. The findings confirm results of a study by Tandi et al. [15] that made known that most tomato farmers in Cameroon had no formal education. This study corroborates the results of Kenko et al. [16] that revealed that the majority of local farmers in the southwest region of Cameroon attained only secondary education.

Table 4 Work-related health complaints as reported by participants, Cameroon, $2017(N=104)$

\begin{tabular}{lll}
\hline Health complaints & Yes & No \\
& $N(\%)$ & $N(\%)$ \\
\hline Skin irritation & $25(24)$ & $79(76.0)$ \\
Backache & $11(10.6)$ & $93(89.4)$ \\
Nervous system injury & $10(9.6)$ & $94(90.4)$ \\
Visual problems & $17(16.3)$ & $87(83.7)$ \\
Respiratory difficulty & $5(4.8)$ & $99(95.2)$ \\
\hline
\end{tabular}

The findings are, however, not in line with the study conducted by Gesesew et al. [17] in southwest Ethiopia which revealed that about two thirds $(67.5 \%)$ of participants could read and understand labels/instructions from the pesticide container if written in the local language.

The analysis revealed that fungicides, insecticides, and herbicides were the pesticides used on tomatoes in the area of study. In addition, insecticides were the most used while herbicides were the least used pesticides. This implies that fungi, insects, and herbs are the major hindrance to production of tomatoes in the study area. This study findings corroborates a study by Tandi et al. [15] conducted in the southwestern region of Cameroon that

Table 5 The correlation between participants' gender and the practice of $\mathrm{OHS}(\mathrm{N}=104)$

\begin{tabular}{|c|c|c|c|c|}
\hline \multirow[t]{2}{*}{ Characteristics } & \multicolumn{2}{|l|}{ Gender } & \multirow{2}{*}{$\begin{array}{l}\text { Total } \\
\text { N (\%) }\end{array}$} & \multirow[t]{2}{*}{$x^{2}(p$ value $)$} \\
\hline & $\begin{array}{l}\text { Male } \\
N(\%)\end{array}$ & $\begin{array}{l}\text { Female } \\
N(\%)\end{array}$ & & \\
\hline \multicolumn{5}{|c|}{ Use of safety boots } \\
\hline Yes & $81(89.0)$ & 10(11.0) & $91(100.0)$ & \multirow[t]{2}{*}{$3.820(0.044)^{*}$} \\
\hline No & $9(69.2)$ & $4(30.8)$ & 13(100.0) & \\
\hline \multicolumn{5}{|c|}{ Use of safety glasses } \\
\hline Yes & $30(90.9)$ & $3(9.1)$ & $33(100.0)$ & \multirow[t]{2}{*}{$0.792(0.373)$} \\
\hline No & $60(84.5)$ & $11(15.5)$ & $71(100.0)$ & \\
\hline \multicolumn{5}{|l|}{ Use of gloves } \\
\hline Yes & $44(86.3)$ & $7(13.7)$ & $51(100.0)$ & \multirow[t]{2}{*}{$0.006(0.938)$} \\
\hline No & $46(86.8)$ & $7(13.2)$ & $53(100.0)$ & \\
\hline \multicolumn{5}{|c|}{ Use of nose mask } \\
\hline Yes & 55(79.7) & 14(20.3) & $69(100.0)$ & \multirow[t]{2}{*}{$8.206(0.004)^{* *}$} \\
\hline No & $35(100)$ & $0(0.0)$ & $35(100.0)$ & \\
\hline \multicolumn{5}{|c|}{ Use of raincoats } \\
\hline Yes & 33(89.2) & $4(10.8)$ & $37(100.0)$ & \multirow[t]{2}{*}{$0.346(0.556)$} \\
\hline No & $57(85.1)$ & 10(14.9) & $67(100.0)$ & \\
\hline \multicolumn{5}{|c|}{ Clean up the body immediately after the use of pesticides } \\
\hline Yes & 1(100.0) & $0(0.0)$ & $1(100.0)$ & \multirow[t]{2}{*}{$0.157(0.692)$} \\
\hline No & 89(86.4) & 14(13.6) & 103(100.0) & \\
\hline
\end{tabular}


found that insecticides, fungicides, and herbicides are the most frequently used pesticides by tomato cultivators to control pests, with insecticides being the most used. Also, the least used pesticides according to Tandi et al. [15] was herbicide, this was probably due to the fact that most farmers did manual weeding of their farms with their family members or friends using hands, cutlasses, and hoes on the smaller farms.

The majority of tomato farmers burned empty pesticide containers or disposed it in the fields. The indiscriminate disposal of these containers in the field could cause the accumulation of pesticide in soil and water sources, as was previously detected in a sample of irrigation water [18]. Some pesticides' active ingredients might not decompose in the soils or water and can therefore be attributed to as the cause for pesticide residues in tomatoes. This practice of indiscriminate disposal of pesticide containers in the fields have been reported in Tanzania [19], as well as Khan, Shabbir, Majid, Naqvi, and Khan [20] in Arumeru-Tanzania and Pakistan.

The current findings showed that the majority of the tomato farmers in the study area have poor OHS practices as a result of inadequate OHS training and use of PPE. Good practices in OHS generally require respondents to comply with OHS practices during the execution of their duties and lead to more positive health and safety culture among the workers and can significantly reduce both injury rates and costs at the workplace [21]. Comparable preceding studies conducted in Cameroon and the Philippines revealed that the use of PPE was rare among participants [22, 23]. Asongwe et al. [22] revealed that $95 \%$ of farmers in Bamenda Municipality of Cameroon do not protect themselves during pesticide applications. In addition, Palis et al. [23] made known that those Filipino farmers believe in immunity, meaning that the youths were not susceptible to the adverse health effects of pesticides. Consequently, PPE were not important to them [23]. The present study findings contradict the result of a study by Negatu et al. [24] conducted in Ethiopia, which reported that $100 \%$ of participants used PPE.

Regarding the work-related problems sustained by farmers, current findings showed that the common work-related problems were skin irritation, backache, nervous system injury such as headache and dizziness, visual problems, and respiratory difficulties after spraying pesticides. Generally, farmers believe that pesticide poisoning symptoms are ordinary so they get used to them [23]. Comparable studies carried out in Tanzania [25] and the Ivory coast [26] reported that pesticide applicators were likely to accept a certain level of illness as an expected and normal part of farming and never reported the symptoms to health centres for prescribed medical assistance.

\subsection{Limitation of the study}

The current findings are limited by the cross-sectional nature of the study design, with tomato farmers recalling information and increasing the possibility of misclassification of exposure and health presentation. Nevertheless, by retraining the researcher's analysis to farmers cultivating tomatoes limited the potential for exposure misclassification. Furthermore, there is the limitation of analysis of blood-pesticide residue of the people that were exposed to pesticides due to the unavailability of facilities.

\section{Conclusion and recommendations}

Findings confirmed that working in small-scale tomato farming might be unsafe, due to poor OHS conditions leading to the predisposing of farmers to the risk of work-related health problems. Exposure to occupational hazards can be significantly reduced if the required PPE are used. Increasing farmers' awareness on good practices for pesticide application and the strengthening of food safety control services for pesticide control as measures to prevent and protect public health against pesticides is recommended. This study concentrated on pesticides used within the western region of Cameroon; future studies should examine blood-pesticide levels, given the high exposure in other regions of the country, to enable the development of a national strategic plan to address pest control and pesticide use.

\section{Abbreviations \\ CNS: Central nervous system; FAO: Food and Agriculture Organization; GDP: Gross domestic product; MINADER: Ministry of Agriculture and Rural Development; OHS: Occupational health and safety; PPE: Personal protective equipment; WHO: World Health Organization}

\section{Acknowledgments}

The authors would like to thank the tomato farmers who participated in this study.

\section{Authors' contributions}

This work was carried out in collaboration among authors. ABT formulated the title and analysed and interpreted the results. BMRM participated in the data collection and data analysis. DLN revised the results and discussion. MGN participated in the study planning and took the responsibility of the administrative aspects of the research. All authors took part in the manuscript preparation and approved the final version of the manuscript.

\section{Funding}

The project is self-funded by the authors.

\section{Availability of data and materials}

All data generated or analysed during this study are included in this published article [and its supplementary information files].

\section{Ethics approval and consent to participate}

This study was approved by the Regional Ethics Committee of the University of Montagnes in Banganté-Cameroon. Before conducting interviews, the research goals, objectives, and the nature of the study were clearly explained to the participants and their questions, if there were any, were appropriately answered. All farmers signed informed consent, confirming that they were willing to participate in the study, by means of interviews. The study complies with the Helsinki Declaration. 


\section{Consent for publication}

Not applicable. The paper does not involve the use of any individual person's data.

\section{Competing interests}

The authors declare that they have no competing interests.

\section{Author details}

${ }^{1}$ Centre for Food and Nutrition Research, Institute of Medical Research and Medicinal Plant Studies (IMPM), MINRESI, P.O. Box 13033, Yaoundé,

Cameroon. ${ }^{2}$ Division of Human Nutrition, Department of Global Health,

Stellenbosch University, P.O. Box 241, Cape Town, South Africa. ${ }^{3}$ Department of Social Work, Faculty of Social Sciences, Linnaeus University, Växjö, Sweden.

Received: 28 November 2018 Accepted: 23 May 2019

Published online: 18 June 2019

\section{References}

1. Johnston BF, Mellor JW. The role of agriculture in economic development. AgEcon Rev. 2007;51:566-3.

2. Sonchieu J, Ngassoum MB, Akono NE, Laxman Prasad S. Pesticide applications on some vegetables cultivated and health implications in Santa, North West-Cameroon. SSRG Int J Agric Environ Sci (SSRG-IJAES). 2017:4(2):39-46.

3. World Health Organization (WHO). Informal consultation on planning strategy for the prevention of pesticide poisoning. Geneva: World Health Organization; 1986.

4. Pretty J, Bharucha ZP. Integrated pest management for sustainable intensification of agriculture in Asia and Africa. Insects. 2015:6(1):152-82.

5. Yanez L, Ortiz D, Calderon J, Batres L, Carrizales L, Mejia J, Martinez L, GarciaNieto $E$, Diaz-Barriga F. Overview of human health and chemical mixtures: problems facing developing countries. Environ Health Perspect. 2002; 110(Suppl 6):901-9.

6. Carvalho FP. Agriculture, pesticides, food security and food safety. Environ Sci Pol. 2006;9(7-8):685-92.

7. Mancini F, Van Bruggen AH, Jiggins JL, Ambatipudi AC, Murphy H. Acute pesticide poisoning among female and male cotton growers in India. Int J Occup Environ Health. 2005;11(3):221-32.

8. Oesterlund AH, Thomsen JF, Sekimpi DK, Maziina J, Racheal A, Jors E. Pesticide knowledge, practice and attitude and how it affects the health of small-scale farmers in Uganda: a cross-sectional study. Afr Health Sci. 2014; 14(2):420-33.

9. FAO. Prevention and disposal of obsolete and unwanted pesticide stocks in Africa and the Near East - Fourthconsultation meeting. Rome: Food and Agriculture Organization of the United Nations; 1999.

10. Asante BO, Osei MK, Dankyi AA, Berchie JN, Mochiah MB, Lamptey JNL, Haleegoah J, Bolfrey-Arku Osei KG. Producer characteristics and determinants of technical efficiency of tomato based production systems in Ghana. J Dev Agric Econ. 2013;5(3):92-103.

11. Litchfield MH. Estimates of acute pesticide poisoning in agricultural workers in less developed countries. Toxicol Rev. 2005;24(4):271-8.

12. Jeyaratnam J. Acute pesticide poisoning: a major global health problem. World Health Stat Q. 1990;43(3):139-44.

13. London L, Bailie R. Challenges for improving surveillance for pesticide poisoning: policy implications for developing countries. Int J Epidemiol. 2001;30(3):564-70

14. Tarla DN, Manu IN, Tamedjouong ZT, Kamga A, Fontem DA. Plight of pesticide applicators in Cameroon: case of tomato (Lycopersiconesculentum Mill.) farmers in Foumbot. JAES. 2015;4(2):87-98.

15. Tandi TE, Wook CJ, Shendeh TT, Eko EA, Afoh CO. Small-scale tomato cultivators' perception on pesticides usage and practices in Buea Cameroon. Health. 2014;6:2945-58. https://doi.org/10.4236/health.2014.621333.

16. Kenko NDB, Asanga BFP, Ngameni TN, Mpoame M. Environmental and human health assessment in relation to pesticide use by local farmers and the Cameroon development corporation (CDC), Fako division, South-West Cameroon. ESJ. 2017;13(21):1857-7431.

17. Gesesew HA, Woldemichael K, Massa D, Mwanri L. Farmers knowledge, attitudes, practices and health problems associated with pesticide use in rural irrigation villages, Southwest Ethiopia. PLoS One. 2016;11(9):e0162527. https://doi.org/10.1371/journal.pone.0162527.
18. Damalas CA, Koutroubas SD. Farmers' exposure to pesticides: toxicity types and ways of prevention. Toxics. 2016;4(1). https://doi.org/10.3390/ toxics4010001.

19. Lekei $E E$, Ngowi AV, London L. Farmers' knowledge, practices and injuries associated with pesticide exposure in rural farming villages in Tanzania. BMC Public Health. 2014;14:1-13.

20. Khan DA, Shabbir S, Majid M, Naqvi TA, Khan FA. Risk assessment of pesticide exposure on health of Pakistani tobacco farmers. J Expo Sci Environ Epidemiol. 2010;20:196-204. https://doi.org/10.1038/jes.2009.13.

21. Wolska L, Namies'nik J. Quality and environmental management systems in Polish shipbuilding industry. Methods of implementation. Pol J Environ Stud. 2007;16(3):459-65.

22. Asongwe GA, Yerima BPK, Tening AS. Vegetable production and the livelihood of farmers in Bamenda municipality. Cameroon Int J Curr Microbiol App Sci. 2014:3(12):682-700.

23. Palis GF, Warburton RJH, Mahabub H. Our farmers at risk: behaviour and belief system in pesticide safety. J Public Health. 2006;28(1):4348. https://doi. org/10.1093/pubmed/fdi066.

24. Negatu B, Kromhout H, Mekonnen Y, Vermeulen R. Use of chemical pesticides in Ethiopia: a cross sectional comparative study on knowledge, attitude and practice of farmers and farm workers in three farming systems. Ann Occup Hyg. 2016;60(5):551-66. https://doi.org/10.1093/annhyg/ mew004 PMID: 26847604.

25. Ngowi AVF, Mbise T, ljani ASM, London L, Ajayi OC. Pesticides use by smallholder farmers in vegetable production in northern Tanzania. Crop Prot 2007: Nov:26(11):1617-24.

26. Ajayi OC. Pesticide use practices, productivity and farmer's health: the case of cotton-rice systems in Cote d'Ivoire, West Africa. Hannover, Germany: A publication of the Pesticide Policy Project; 2000. p. 172. (Special Issue Publication Series, No. 3).

\section{Publisher's Note}

Springer Nature remains neutral with regard to jurisdictional claims in published maps and institutional affiliations.

\section{Submit your manuscript to a SpringerOpen ${ }^{\circ}$ journal and benefit from:}

- Convenient online submission

- Rigorous peer review

- Open access: articles freely available online

High visibility within the field

- Retaining the copyright to your article

Submit your next manuscript at $\boldsymbol{\nabla}$ springeropen.com 